\title{
RESISTÊNCIA DE AMENDOIM-BRAVO AOS HERBICIDAS INIBIDORES DA ENZIMA ACETOLACTATO SINTASE ${ }^{1}$
}

\author{
RIBAS A. VIDAL ${ }^{2}$ e ALDO MEROTTO JR. ${ }^{3}$
}

\section{RESUMO}

O controle contínuo de plantas daninhas através da aplicação de herbicidas que apresentam atividade em um único local de ação nas plantas favorece a seleção de biótipos resistentes a estes herbicidas, em certas espécies vegetais. Quatro experimentos foram conduzidos em condições casa-de-vegetação, na Faculdade de Agronomia da Universidade Federal do Rio Grande do Sul, com os objetivos de avaliar a ocorrência de resistência aos herbicidas inibidores da enzima acetolactato sintase (ALS) em vários biótipos de leiteiro ou amendoim-bravo (Euphorbia heterophylla EPHHL) e avaliar a ocorrência de resistência múltipla a herbicidas com atividade em outros locais de ação. Biótipo oriundo de Passo Fundo foi resistente ao imazethapyr, enquanto biótipo oriundo de Porto Alegre foi suscetível. O biótipo de Passo Fundo apresentou resistência cruzada aos herbicidas imidazolinonas: imazapyr, imazaquin e imazethapyr; sulfoniluréias: chlorimuron, nicosulfuron e metsulfuron; e sulfonanilida: flumetsulan. Este biótipo não foi resistente aos herbicidas com os seguintes mecanismos de ação: inibidores de EPSPs, mimetizadores de auxina, inibidores dos fotossistemas I e II e inibidores de PROTOX. A confirmação de resistência aos inibidores de ALS em biótipos oriundos de Nãome-Toque, Passo Fundo e Rio Pardo sugere ampla dispersão no Rio Grande do Sul de resistência de E. heterophylla aos herbicidas deste mecanismo de ação.

Palavras chave: Euphorbia heterophylla, imidazolinona, sulfoniluréia, sulfonanilida, resistência a herbicidas.

\section{ABSTRACT \\ Wild poinsettia resistance to acetolactate synthase inhibitor herbicides}

The continuous weed control with herbicides of only one site of action selects biotypes resistant to these herbicides. Four experiments were conducted in greenhouse of UFRGS, Brazil, to confirm the occurence of wild poinsettia (Euphorbia heterophylla) biotypes resistance to herbicides inhibitors of acetholactate synthase (ALS), and to determine whether there was cross resistance to herbicides with other site of action. A biotype from Passo Fundo - RS was resistant to imazethapyr, whereas a biotype from Porto Alegre - RS was susceptible to this compound. The biotype from Passo Fundo was resistant to the following ALS-inhibitors: imazapyr, imazaquin, imazethapyr, chlorimuron, nicosulfuron, metsulfuron e flumetsulan. This biotype was not resistant to herbicides from the following modes of action: EPSPs inhibitors, auxin agonists, fotossystems I and II inhibitors, and PROTOX inhibitors. The confirmation of resistance to ALS inhibitors in biotypes from Não-me-Toque, Passo Fundo and Rio Pardo suggests a wide spread of wild

\footnotetext{
${ }^{1}$ Recebido para publicação em 16/10/98 e na forma revisada em 25/02/99.

${ }^{2}$ Eng $^{\circ} \mathrm{Agr}^{\circ}$, Ph. D., docente da Faculdade de Agronomia da Universidade Federal do Rio Grande do Sul. C.P. 776, CEP: 90001970, Porto Alegre/RS, Brasil. Bolsista do CNPq. E-mail: vidal@if1.if.ufrgs.br

${ }^{3}$ Eng $^{\circ}$ Agr $^{\circ}$, M. Sc., docente da Universidade Federal do Rio Grande do Sul. C.P. 776, CEP: 90001-970, Porto Alegre/RS, Brasil.
} 
poinsettia resistance to compounds of this mode of action in the Rio Grande do Sul state.

Key words: Euphorbia heterophylla, imidazolinone, sulfonylurea, sulfonanilide, herbicide resistance.

aos inibidores de ALS e Brachiaria plantaginea resistente aos inibidores de ACCase.

E. heterophylla é uma das dicotiledôneas

O aparecimento de biótipos de plantas daninhas resistentes aos herbicidas depende de características relacionadas às planta daninha, ao herbicida e ao manejo da cultura. Com relação ao herbicida, o principal fator que favorece o desenvolvimento da resistência é a utilização constante de herbicidas que atuam em um único local de ação nos vegetais (Vidal, 1997). Em nível mundial, registra-se anualmente o aparecimento de cerca de 10 novas espécies resistentes aos herbicidas (Heap, 1997).

A seleção para resistência é favorecida pela utilização de diferentes produtos com mesmo mecanismo de ação em diversas culturas cultivadas em rotação. No Brasil são utilizados diversos herbicidas inibidores da enzima acetolactato sintase (ALS) pertencentes a diferentes grupos químicos, destacando-se as imidazolinonas (imazapyr, imazaquin e imazethapyr), as sulfoniluréias (chlorimuron-etil, metsulfuron-metil e nicosulfuron) e as sulfonanilidas (flumetsulam). Esses herbicidas apresentam registro para as culturas de milho, soja e trigo, o que possibilita o uso contínuo deste mecanismo de ação, constituindo, então, fator de risco para o desenvolvimento de biótipos resistentes aos mesmos (Vidal, 1997).

No mundo, os primeiros casos de resistência aos inibidores de ALS foram registrados com Lactuca serriola e Kochia scoparia em apenas cinco anos de uso deste grupo de herbicidas (Mallory-Smith et al., 1990; Primiani et al., 1990). No Brasil, a resistência aos herbicidas foi documentada em 1996, com biótipos de Bidens pilosa (B. subalternans) resistentes aos inibidores de ALS (Ponchio et al., 1996). Em 1997, Vidal \& Fleck (1997a) documentaram a existência de 3 espécies daninhas brasileiras com resistência aos herbicidas: Bidens $s p$. e Euphorbia heterophylla (EPHHL) resistentes com maior incidência na região sul do Brasil, estando presente em $74 \%$ das áreas de soja na região do Planalto do Estado do Rio Grande do Sul (Bianchi, 1996). Esta espécie apresenta como centro de origem a América tropical, estando distribuída na maioria dos países das Américas, Africa e Ásia (Kissmann \& Groth, 1992; Holm et al., 1997). Apresenta ciclo de vida anual e pode iniciar o florescimento entre 20 e 30 dias após a emergência das plantas (Holm et al., 1997).

A principal causa da resistência aos inibidores de ALS é presença de isoenzima de ALS insensível à ação dos herbicidas (Vidal, 1997). Neste caso, os biótipos são resistentes a vários herbicidas que atuam na mesma enzima. Para o manejo destes biótipos resistentes é importante avaliar se ocorre resistência múltipla aos herbicidas com atuação em outras enzimas no vegetal. Este trabalho objetivou confirmar a ocorrência de resistência aos herbicidas inibidores de acetolactato sintase (ALS) em vários biótipos de E. heterophylla e avaliar se há resistência múltipla aos herbicidas de outros mecanismos de ação.

\section{MATERIAL E MÉTODOS}

Foram conduzidos quatro experimentos em casa-de-vegetação da Faculdade de Agronomia da Universidade Federal do Rio Grande do Sul, localizada no município de Porto Alegre, RS. Para confirmação da resistência aos inibidores de ALS, sementes de E. heterophylla foram coletadas em aproximadamente 100 plantas presentes em propriedades localizadas em quatro municípios do Rio Grande do Sul. As sementes foram coletadas entre maio de 1996 e maio de 1997 e após a coleta, as sementes foram armazenadas sob temperatura constante de $4^{\circ} \mathrm{C}$ até a realização dos 
experimentos. As propriedades localizadas nos municípios de Não-me-Toque, Passo Fundo e Rio Pardo foram cultivadas por pelo menos 6 anos com soja, recebendo aplicação anual dos herbicidas inibidores de ALS, apresentando áreas com plantas de E. heterophylla sob suspeita de serem resistentes a estes herbicidas. Em Porto Alegre as sementes foram coletadas em plantas que se desenvolveram em local onde não se utilizou herbicidas para servir como testemunha suscetível aos inibidores de ALS.

Todos experimentos foram desenvolvidos entre setembro e novembro de 1997, utilizando-se vasos plásticos com capacidade de $400 \mathrm{~cm}^{3}$ de solo. O substrato consistiu de solo Podzólico Vermelho-Escuro distrófico, coletado da Estação Experimental Agronômica da UFRGS, no município de Eldorado do Sul, e apresentava teor de matéria orgânica de $2,1 \%$; teor de argila de $35 \%$; pH em água de 5,4; fósforo disponível de $20 \mu \mathrm{g} \cdot \mathrm{g}^{-1}$ e potássio trocável de $140 \mu \mathrm{g} \cdot \mathrm{g}^{-1}$. Colocou-se aproximadamente dez sementes por vaso e após a germinação procedeu-se o desbaste para quatro plântulas. Os vasos foram mantidos em bandejas plásticas contendo água, para manter o solo constantemente irrigado por capilaridade. A temperatura diurna e noturna na casa-de-vegetação foi de $29 \pm 5$ e $20 \pm 6 \mathrm{C}$, respectivamente. Durante a realização do experimento procedeu-se à casualização da distribuição dos vasos a cada 5 dias, para minimizar a variabilidade das condições da casa-de-vegetação.

Para confirmar a resistência, desenvolveuse experimento com dois biótipos utilizando-se delineamento completamente casualizado com tratamentos organizados em esquema fatorial com 3 repetições, de acordo com método descrito por Ryan (1970), onde o Fator A foram os biótipos (Passo Fundo e Porto Alegre) e o fator B foram doses de imazethapyr. Para o biótipo suspeito de resistência (Passo Fundo) as doses do herbicida foram $0,50,100,400$ e $800 \mathrm{~g} / \mathrm{ha}$, enquanto para o biótipo suscetível as doses foram $0,25,50,100 \mathrm{e}$ $400 \mathrm{~g} / \mathrm{ha}$.

O herbicida foi aspergido aos 20 dias após a emergência de E. heterophylla, quando as plantas apresentavam 4 folhas, utilizando-se equipamento pressurizado a gás carbônico, com bicos 8002 VS, pressão de $200 \mathrm{kPa}$ e volume de calda de 200 1/ha, adicionando-se à calda de aplicação óleo mineral a 1,5 1/ha. Trinta dias após a aplicação dos herbicidas (DAT) determinou-se a matéria seca das plantas.

A confirmação da resistência para os biótipos provenientes de Rio Pardo e de Não-meToque foi realizada num outro experimento, de acordo com método sugerido por Ritter \& Menbere (1993). Sementes dos biótipos com comportamento desconhecido (Rio Pardo e Nãome-Toque) e dos padrões resistente (Passo Fundo) e suscetível (Porto Alegre), estudados no experimento anterior, foram semeadas em vasos para avaliar o desempenho de imazethapyr, aspergido a $250 \mathrm{~g} / \mathrm{ha}$ com equipamentos e demais procedimentos descritos anteriormente. Aos 25 DAT, determinou-se o número de plantas sobreviventes aos tratamentos herbicidas.

Para avaliação de resistência cruzada a outros inibidores de ALS, sementes do biótipo proveniente de Passo Fundo foram semeadas conforme descrito anteriormente. Utilizou-se delineamento inteiramente casualizado com três repetições, contendo cada uma três plantas. Aos 20 dias após a emergência, quando as plantas de $E$. heterophylla apresentavam 4 folhas, aplicaram-se os herbicidas chlorimuron, flumetsulan, imazapyr, imazaquin, imazethapyr, metsulfuron e nicosulfuron (doses na Tabela 1), conforme equipamento e procedimentos já descritos anteriormente. Aos 21 DAT, avaliaram-se a área foliar e a injúria causada pelos herbicidas nas plantas de E. heterophylla. A injúria foi avaliada através de escala visual, onde ausência de injúria correspondeu o valor 0 , enquanto morte da planta correspondeu ao valor 100 .

Para avaliação de herbicidas de outros mecanismos de ação, sementes do biótipo proveniente de Passo Fundo foram semeadas conforme descrito anteriormente. Utilizou-se delineamento inteiramente casualizado com três repetições, contendo cada uma três plantas. Aos 20 dias após a emergência, quando as plantas de $E$. 
heterophylla apresentavam 4 folhas, aplicaramse os herbicidas atrazine, clomazone, dicamba, 2,4-D, fomesafen, glyphosate, lactofen e paraquat (doses na Tabela 2). A aplicação dos herbicidas foi realizada conforme equipamento e procedimentos descritos anteriormente. Aos 35 DAT avaliou-se a injúria causada pelos herbicidas nas plantas de E. heterophylla, utilizando-se escala visual conforme descrito anteriormente.

TABELA 1. Área foliar e injúria em plantas de Euphorbia heterophylla oriundas de Passo Fundo, avaliadas 21 dias após a aplicação de sete herbicidas inibidores de ALS.

UFRGS, Porto Alegre, RS, 1998.

\begin{tabular}{lccc}
\hline Tratamentos & $\begin{array}{l}\text { Dose } \\
\mathrm{g} / \mathrm{ha}\end{array}$ & $\begin{array}{c}\text { Área foliar } \\
\mathrm{cm}^{2} / \text { planta }\end{array}$ & $\begin{array}{c}\text { Injúria } \\
\%\end{array}$ \\
\hline imazapyr & 500 & $9,7^{\mathrm{ns}}$ & $12^{\mathrm{ns}}$ \\
imazaquin & 150 & 10,5 & 2 \\
imazethapyr & 100 & 10,4 & 2 \\
flumetsulan & 120 & 13,3 & 0 \\
chlorimuron & 20 & 14,5 & 0 \\
nicosulfuron & 80 & 9,9 & 0 \\
metsulfuron & 4 & 16,5 & 0 \\
testemunha & - & 12,2 & 0 \\
\hline
\end{tabular}

ns = não significativo, pelo teste $\mathrm{F}$ a $5 \%$ de probabilidade.

TABELA 2. Injúria em plantas de Euphorbia heterophylla oriundas de Passo Fundo, aos 35 dias após a aplicação de herbicidas não inibidores de ALS.

UFRGS, Porto Alegre, RS, 1998.

\begin{tabular}{lcrc}
\hline Herbicidas & $\begin{array}{c}\text { Dose } \\
\text { g/ha }\end{array}$ & \multicolumn{2}{c}{$\begin{array}{l}\text { Injúria } \\
\%\end{array}$} \\
\hline atrazine & 2000 & $100 \pm$ & 0 \\
dicamba & 192 & $76 \pm$ & 3 \\
2,4-D & 800 & $93 \pm$ & 7 \\
fomesafen & 250 & $68 \pm$ & 14 \\
glyphosate & 720 & $100 \pm$ & 0 \\
lactofen & 180 & $73 \pm$ & 9 \\
paraquat & 400 & $100 \pm$ & 0 \\
& & & \\
\hline
\end{tabular}

${ }^{1}$ As médias são acompanhadas do erro padrão. 
Em todos experimentos os dados foram submetidos à análise de variância e, quando o teste F para tratamentos foi significativo, calculou-se o erro padrão das médias para auxiliar nas comparações das médias dos tratamentos.

\section{RESULTADOS E DISCUSSÃO}

Imazethapyr, aplicado na dose recomendada $(100 \mathrm{~g} / \mathrm{ha})$, reduziu em $85 \%$ a matéria seca de E. heterophylla oriundo de Porto Alegre (Figura 1), confirmando que este biótipo é suscetível aos inibidores de ALS. Já o biótipo oriundo de Passo Fundo, não foi afetado por imazethapyr, mesmo quando aspergido em dose 8 vezes superior à recomendada. Estes resultados indicam que o biótipo oriundo de Passo Fundo é resistente ao herbicida imazethapyr, o qual foi utilizado por longo período na propriedade onde foram coletadas as sementes.

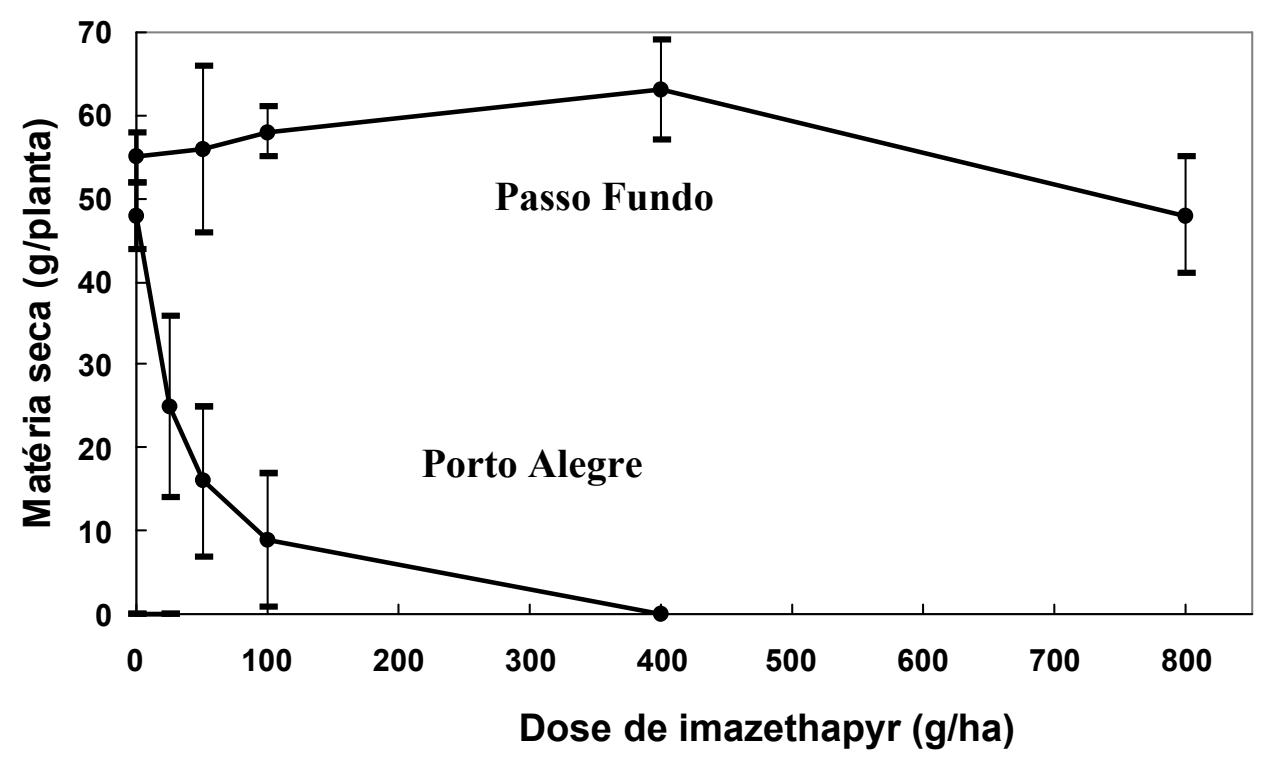

FIGURA 1. Matéria seca de dois biótipos de Euphorbia heterophylla aos 30 dias após a aplicação de diversas doses de imazethapyr. Barras verticais indicam erro padrão da média. UFRGS, Porto Alegre, RS, 1998.

A área foliar das plantas do biótipo proveniente de Passo Fundo não foi afetada por outros herbicidas inibidores de ALS (Tabela 1). Da mesma forma, não se observou injúria nas plantas deste biótipo para os herbicidas inibidores de ALS testados (Tabela 1), confirmando a hipótese de que a resistência não é específica apenas para imazethapyr, mas para os demais herbicidas com o mesmo mecanismo de ação (Tabela 1). Em outros trabalhos realizados a nível mundial, também se observou que as plantas daninhas selecionadas com um inibidor de ALS também apresentavam resistência cruzada a outros compostos com atividade na mesma enzima (Mallory-Smith et al., 1990; Primiani et al., 1990). Imazethapyr, a $250 \mathrm{~g} / \mathrm{ha}$, não afetou $\mathrm{o}$ crescimento e o desenvolvimento dos biótipos oriundos de Não-me-Toque, Passo Fundo e Rio Pardo, mas controlou todas as plantas oriundas de Porto Alegre, confirmando que os 3 primeiros biótipos são resistentes aos inibidores de ALS. O histórico do controle de plantas daninhas nas áreas onde foram coletadas as sementes dos biótipos nestes 3 municípios é parecido, utilizando-se herbicidas inibidores de ALS por diversos anos e realizando-se monocultura de soja, o que deve ter favorecido a evolução da resistência. A 
confirmação de resistência aos inibidores de ALS em biótipos oriundos de Não-me-Toque, Passo Fundo e Rio Pardo sugere ampla dispersão no Rio Grande do Sul de resistência de E. heterophylla aos herbicidas deste mecanismo de ação. Além disto, como o centro de origem de E. heterophylla está, em parte, compreendido no Brasil (Kissmann \& Groth, 1992; Holm et al., 1997), especula-se que ocorre grande diversidade genética desta espécie no país, o que explicaria uma provável elevada freqüência do gene de resistência aos herbicidas (Vidal \& Fleck, 1997b).

Observou-se que ocorre diversidade foliar entre os biótipos testados, sendo que os biótipos provenientes de Não-me-Toque e Passo Fundo apresentaram folhas ovaladas, o biótipo de Porto Alegre apresentou folhas panduriformes com bordas serrilhadas e o biótipo de Rio Pardo apresentou folhas inferiores lanceoladas e superiores panduriformes. Na tabela 2 apresentamse os resultados do controle de plantas de $E$. heterophylla do biótipo proveniente de Passo Fundo com herbicidas de diversos mecanismos de ação. As plantas foram controladas por herbicidas totais como 2,4-D (mimetizador de auxina), glyphosate (inibidor de EPSPs) e paraquat (inibidor de fotossistema I) (Tabela 2). Isto sugere que a utilização destes herbicidas na dessecação das plantas daninhas antes da semeadura da cultura no sistema de semeadura direta pode ser uma estratégia de controle de E. heterophylla resistente aos inibidores de ALS.

E. heterophylla resistente aos inibidores de ALS foi controlada por herbicidas utilizados na cultura de soja como fomesafen e lactofen (inibidores de PROTOX) (Tabela 2), indicando que nesta cultura, estes herbicidas podem ser alternativas para o controle de biótipos resistentes aos inibidores de ALS. Contudo, ressalta-se que algumas plantas rebrotaram a partir de gemas laterais, fazendo o controle médio proporcionado por estes herbicidas se situar na faixa de $70 \%$. Este resultado não decorre da ineficácia dos herbicidas sobre E. heterophylla, mas ao fato de que inibidores de PROTOX eliminam o meristema apical de certas plantas daninhas e que ocorrem rebrotações a partir das gemas laterais devido a ausência da dominância apical (Dayan \& Duke, 1997).

Herbicidas utilizados na cultura de milho como atrazine (inibidor de fotossistema II), dicamba e 2,4-D (mimetizadores de auxina) controlaram as plantas resistentes aos inibidores de ALS (Tabela 2). Estes compostos podem ser opções de manejo dos biótipos resistentes em situações em que se empregue a rotação de culturas como estratégia auxiliar para manejo da resistência.

O controle de E. heterophylla com herbicidas de diversos mecanismos de ação (Tabela 2) indica não haver resistência múltipla a herbicidas com outros mecanismos de ação, sugerindo que se podem utilizar estratégias como rotação ou misturas de herbicidas de outros mecanismos de ação, para o manejo dos biótipos resistentes (Vidal, 1997).

\section{AGRADECIMENTOS}

Agradecemos aos srs. M. V. W. Ferri, M. Trezzi, N. D. Kruzi e V. Spader pelas sugestões apresentadas ao texto e aos srs. E. A. Manjabosco e C. M. Carollo pelo apoio parcial na condução dos experimentos.

\section{LITERATURA CITADA}

BIANCHI, M. A. Programa de difusão do manejo integrado de plantas daninhas em soja. In: REUNIÃO DE PESQUISA DE SOJA DA REGIÃO SUL, 23, Porto Alegre, RS. Ata e Resumos... Porto Alegre, UFRGS, 1996, $125 \mathrm{p}$.

DAYAN, F. E.; DUKE, S. O. Overview of protoporphyrinogen oxidase-inhibiting herbicides. In: BRIGHTON CROP PROTECTION CONFERENCE, 1997. Brighton, Inglaterra. Proceedings... BCPC, 1997, v. 1, 442p. p.83-92.

HEAP, I. M. The occurrence of herbicide-resistant weeds worldwide. Pestic. Sci., v.51, p.235234. 1997. 
HOLM, L.; DOLL, J.; HOLM, E.; PANCHO, J.; HERBERGER, J. World weeds: natural histories and distributions. New York: Wiley, 1129p., 1997.

KISSMANN, K. G., GROTH, D. Plantas infestantes e nocivas. São Paulo: BASF, 1992. v.2. 798 p.

MALLORY-SMITH, C. A., THILL, D. C., DIAL, M. J. Identification of sulfonylurea herbicide-resistant prickly lettuce (Lactuca serriola). Weed technol, v. 4, p.163-168, 1990.

PONCHIO, J. A. R., CHRISTOFFOLETI, P. J., MELO, M., VICTORIA FILHO, R. ALS enzyme assay from Bidens pilosa biotypes of the Brazilian soybean areas to determine the sensitivity to imidazolinone and sulfonylurea herbicides. In: WSSA MEETING, 1996. Norfolk, EUA. Proceedings ... WSSA, 1996.

PRIMIANI, M. M., COTTERMAN, J. C., SAARI, L. L. Resistance of kochia (Kochia scoparia) to sulfonylurea and imidazolinone herbicides. Weed technol., v. 4, p. 169-172, 1990.

RITTER, R. L., MENBERE, H. Results of weed control research in 1993. College Park: University of Maryland, 1993. 294p.

RYAN, G. F. Resistance of common groundsel to simazine and atrazine. Weed sci., v. 18, p. 614-616, 1970.

VIDAL, R. A. Herbicidas: mecanismos de ação e resistência de plantas. Porto Alegre: Palotti, 1997. 165p.

VIDAL, R. A., FLECK N. G. Three weed species with confirmed resistance to herbicides in Brazil. In: WSSA MEETING, 1997. Orlando, EUA. Proceedings ... WSSA, 1997a.p.100.

VIDAL, R. A., FLECK, N. G. Análise do risco da ocorrência de biótipos de plantas daninhas resistentes aos herbicidas. Planta Daninha, v.15, n.2, p.152-161. 1997b. 